\title{
Unequal Effects of Educational Attainment on Workplace Exposure to Second-Hand Smoke by Race and Ethnicity: Minorities' Diminished Returns in the National Health Interview Survey
}

\author{
Shervin Assari ${ }^{1}$, Mohsen Bazargan ${ }^{1,2}$
}

\begin{abstract}
${ }^{1}$ Department of Family Medicine, College of Medicine, Charles R Drew University of Medicine and Science, Los Angeles, CA 90059, USA, ${ }^{2}$ Department of Family Medicine, University of California, Los Angeles, Los Angeles, CA 90095, USA

Address for correspondence: Shervin Assari, Department of Family Medicine, Charles R Drew University of Medicine and Science, Los Angeles, CA 90059, USA. E-mail: assari@umich.edu
\end{abstract}

\section{Abstract}

Background: One of the mechanisms by which high educational attainment promotes populations' health is through reducing exposure to environmental risk factors such as second-hand smoke. Minorities' Diminished Returns theory, however, posits that the protective effect of educational attainment may be smaller for racial and ethnic minority individuals, particularly Blacks and Hispanics compared to Whites. Aims: This study aims to explore racial and ethnic differences in the association between educational attainment and second-hand smoke exposure at work in a national sample of American adults. Methods: Data came from the National Health Interview Survey 2015, a cross-sectional study included 15,726 employed adults. The independent variable was educational attainment, the dependent variables were any and daily second-hand smoke exposure at workplace, age and gender were covariates, and race and ethnicity were the moderators. Results: Overall, higher educational attainment was associated with lower odds of any and daily second-hand smoke exposure at work. Race and ethnicity both interacted with educational attainment, suggesting that the protective effects of educational attainment on reducing the odds of any and daily second-hand smoke exposure at work are systemically smaller for Blacks and Hispanics than Whites. Conclusion: In the United States, race and ethnicity bound the health gains that follow educational attainment. While educational attainment helps individuals avoid environmental risk factors such as second-hand smoke, this is more valid for Whites than Blacks and Hispanics. The result is additional risk of cancer and tobacco-related disease in highly educated Blacks and Hispanics. The results are important given racial and ethnic minorities are the largest growing section of the US population. We should not assume that educational attainment is similarly protective across all racial and ethnic groups. In this context, educational attainment may increase, rather than reduce, health disparities.

Keywords: Population groups, Ethnicity, Race, Hispanics, Latinos, Whites, Blacks, African Americans, Socioeconomic position, Socioeconomic status, Education, Smoking, tobacco use, Second-hand smoke, work, Employment

\section{Background}

Tobacco is the leading preventable cause of disease and premature death in the United States. ${ }^{[1,2]}$ About 480,000 Americans die from tobacco-related illnesses annually. In addition, more than 16 million Americans are impacted by diseases caused by smoking. ${ }^{[3-6]}$ These cost the US more than $\$ 300$ billion each year, which is composed of $\$ 170$ billion and $\$ 156$ billion for direct and indirect costs. ${ }^{[7]}$

Unfortunately, there is an unequal burden of tobacco use in the US. Despite a lower prevalence of smoking, Blacks and Hispanics are more likely

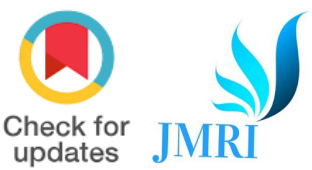

How to cite this article: Assari S, Bazargan M. Unequal Effects of Educational Attainment on Workplace Exposure to Second-Hand Smoke by Race and Ethnicity: Minorities' Diminished Returns in the National Health Interview Survey. J Med Res Innov. 2019;3(2):e000179.

DOI: 10.32892/jmri.179

Publication history: Received: 15-07-2019 Accepted: 23-07-2019

Published: 24-07-2019

Editor: Dr. Shakti Goel

Copyright: Assari S,

Bazargan M. This is an open-access article distributed under the terms of the Creative Commons Attribution License CC-BY 4.0., which permits unrestricted use, distribution, and reproduction in any medium, provided the original author and source are credited.

Funding: Research reported in this publication was supported by the National Cancer Institute of the National Institutes of Health (NIH) and FDA Center for Tobacco Products (CTP) under Award Number U54CA229974.

The content is solely the responsibility of the authors and does not necessarily represent the official views of the NIH or the Food and Drug Administration. Bazargan is supported by the Center for Medicare and Medicaid Services (CMS) Grant 1H0CMS331621 as well as the NIH Awards 54MD008149", R25 MD007610, 2U54MD007598, and U54 TR001627. Assari is also supported by the National Cancer Institute $(\mathrm{NCl})$ grant CA201415-02 (Co-PI = R. Mistry). Publicly available data set was downloaded from the NHIS website at CDC. The $\mathrm{NHIS}$ is funded by the CDC.

Conflicts of Interest: NIL

\section{MK Medkrux}




\section{Assari and Bazargan: Race, Employment, and Second-Hand Smoke Exposure}

to be impacted by tobacco-related conditions and illnesses. $^{\left[{ }^{8]}\right.}$ A higher burden of tobacco-related illnesses despite lower prevalence of tobacco use is in part due to high levels of second-hand smoke exposure in low socioeconomic status (SES) and racial and ethnic minority individuals, ${ }^{\left[{ }^{[9-12]}\right.}$ in addition to a vulnerability ${ }^{[13]}$ which is due to low trust and low access to treatment and the health care. ${ }^{[14-16]}$ Despite the progress in reducing overall morbidity and mortality attributed to smoking, tobacco use has shifted from a mainstream behavior to a behavior which is mainly concentrated among marginalized populations defined by SES, race, and ethnicity. The existing economic and racial and ethnic gap in the burden of tobacco-related disease is a major threat to the progress that has been made thus far.

According to the Minorities' Diminished Returns theory (MDRs), ${ }^{[17-19]}$ at least some of the racial/ ethnic disparities are due to "less than expected" protective effects of SES indicators such as educational attainment. ${ }^{[17,20-22]}$ The MDRs theory suggests that (a) racial/ethnic disparities in tobacco use are not all due to SES gaps but also due to differential health gains that follow high SES for Black and Hispanic populations, (b) the racial and ethnic gap in tobacco use widens at higher SES levels, and (c) there is a need to address racial/ ethnic disparities across all SES levels. ${ }^{[17-19]}$ Some evidence suggests that MDRs also apply to tobacco use, meaning that high SES Blacks and Hispanics are more likely to use tobacco and alcohol, compared to high SES Whites. ${ }^{[23-26]}$ We are, however, not aware of any previous studies on MDRs on second-hand smoke exposure.

We conducted this study to test whether race and ethnicity interact with educational attainment on workplace second-hand smoke exposure in American adults who were employed. We hypothesized that the protective effects of educational attainment against second-hand exposure are smaller for Blacks and Hispanics than Whites. MDRs are not because of groups' or individuals' characteristics, but rather are due to differential treatment by the society. The US labor market discriminates, and the society marginalizes and stigmatizes Blacks and Hispanics. As a result, highly educated Blacks and Hispanics are more likely to work in low-quality occupations that increase their exposure to a wide range of environmental exposures such as second-hand smoke. In addition, due to residential segregation, highly educated Blacks and Hispanics are more likely to live in unsafe poor areas that have poor job opportunities. Thus, educational attainment does not similarly protect the marginalized groups. This differential treatment becomes MDRs of educational attainment for Blacks and Hispanics.

\section{Methods \\ Design and settings}

This is a secondary analysis of the 2015 National Health Interview Survey (NHIS) data. Funded by the Centers for Disease Control (CDC), NHIS is one of the main national health surveys of Americans. Data were collected in 2015.

\section{Data retrieval}

We used publicly available NHIS data sets, downloaded from the NHIS/CDC website. We merged personal, individual, and cancer data sets, using the subject and family IDs. Although the NHIS 2015 includes 33,672 adults (from all race and ethnicities and including employed and non-employed), the current analysis only includes 15,726 employed adults who were either White or Black.

\section{Sample and sampling}

The NHIS population was the civilian, noninstitutionalized US population, 18 years of age and older individuals in the US. The NHIS uses a multistage, clustered, and stratified area probability sample design.

\section{Analytical sample}

The current analysis is limited to adults who were either White or Black and had valid data on tobacco use. Our final analytical sample was 15,726 employed White or Black adults.

\section{Study variables}

The study variables include demographic factors (age and gender), race, ethnicity, educational attainment (SES), and tobacco use, all measured at the individual level.

\section{Demographic characteristics}

Confounders were age and gender. Age was a continuous measure. Gender was a dichotomous variable (male 1 and female 0 ). Race was selfidentified as was either Blacks or Whites. Ethnicity 


\section{Assari and Bazargan: Race, Employment, and Second-Hand Smoke Exposure}

was self-identified and was Hispanics versus nonHispanics. Years at this job were measured as self-report and treated as a continuous measure, ranging from 0 to 36 years. Having more than one job was a dichotomous variable. Participants were asked if they were working on more than one job. Educational attainment was a continuous measure varying from 0 to 24 years. Marital status was selfreported and included the following categories: (1) Married, (2) widowed, (3) divorced, (4) separated, (5) never married, and (6) living with partner. This variable was treated as a categorical (nominal) variable and married was regarded as the reference group. Region was a four-level categorical variable coded as below: (1) Northeast, (2) Midwest, (3) South, and (4) West. This variable was treated as a categorical (nominal) variable and Northeast was regarded as the reference group. The current smoking was measured using self-reported items that measured if the individual has smoked 100 cigarettes, smokes currently, and smokes daily. Affirmatory answer to all above items was required for the definition of current smokers.

Two outcomes in this study were any and daily workplace second-hand smoke exposures. The participants were asked "How often were your exposed to second-hand smoke at work, during the past 12 months?" Responses were (a) never, (b) less than twice a week, (c) twice a week or more, but not every day, and (d) every day. We recoded these categories to generate two separate outcomes: (1) Daily workplace second-hand smoke exposure and (2) any workplace second-hand smoke exposure.

\section{Conceptual model}

Built on the MDRs theory, we were mainly interested in the diminished returns of educational attainment on second-hand smoke exposure for non-Whites relative to Whites. We conceptualized the MDRS as interaction terms between race and ethnicity with educational attainment (SES).

\section{Data analytical plan}

We analyzed the data using the SPSS 23.0 (IBM Corporation, Armonk, NY, USA). Using SPSS 23.0, we were able to accommodate survey weights due to the design (e.g., stratification, clustering, and non-response). First, we examined the distribution of our categorical and continuous variables. Then, we used Spearman correlation tests to explore unadjusted correlations between the study variables. For multivariable analysis, we applied binary logistic regression. However, we first ruled out collinearity between independent variables. We ran models in the pooled sample.

\section{Ethics}

All adult participants in the NHIS provided written informed consent. NHIS is approved by the Research Ethics Review Board of the National Center for Health Statistics and the U.S. Office of Management and Budget.

\section{Results \\ Descriptive statistics}

This study included 15,726 American adults who were either White $(13,327,84.7 \%)$ or Black $(2399$, $15.3 \%)$. Mean age of the participants was 43.4 (standard deviation $[S D]=14.2$ ) years. On average, participants had 15.8 years (SD $=2.8$ years) as their educational attainment. Table 1 shows descriptive statistics of the overall sample [Table 1].

\section{Bivariate analysis}

Table 2 shows bivariate correlations between the study variables. Educational attainment was inversely correlated with any and daily second-hand smoke exposure. Ethnicity was not correlated with any and daily second-hand smoke exposure. Being Black was, however, positively correlated with any and daily second-hand smoke exposure [Table 2].

\section{Multivariable models (Outcome: Any second-hand smoking exposure)}

Table 3 presents the summary of the results of two logistic regression models with educational attainment as the independent variable and any second-hand smoking exposure as the dependent variable. Both models were estimated in the overall sample. Model 1 only entered the main effects of educational attainment, race, ethnicity, and covariates. Model 2 also added two interaction terms between race and ethnicity with educational attainment. Based on Model 1, high educational attainment was associated with lower odds of any workplace second-hand smoking exposure. Model 2 showed significant interactions between race and ethnicity with educational attainment on any 
Assari and Bazargan: Race, Employment, and Second-Hand Smoke Exposure

Table 1: Descriptive statistics in the overall sample

\begin{tabular}{|c|c|c|}
\hline Characteristics & Mean & SD \\
\hline Age & 43.4 & 14.2 \\
\hline Educational attainment & 15.8 & 2.8 \\
\hline Work at the same job & 8.4 & 9.1 \\
\hline Characteristics & $n$ & $\%$ \\
\hline \multicolumn{3}{|l|}{ Race } \\
\hline White & 13,327 & 84.7 \\
\hline Black & 2399 & 15.3 \\
\hline \multicolumn{3}{|l|}{ Ethnicity } \\
\hline Non-Hispanic & 13,743 & 87.5 \\
\hline Hispanic & 1955 & 12.5 \\
\hline \multicolumn{3}{|l|}{ Gender } \\
\hline Women & 7957 & 50.6 \\
\hline Men & 7769 & 49.4 \\
\hline \multicolumn{3}{|l|}{ Marital status } \\
\hline Married & 7296 & 46.4 \\
\hline Widowed & 430 & 2.7 \\
\hline Divorced & 2279 & 14.5 \\
\hline Separated & 449 & 2.9 \\
\hline Never married & 4070 & 25.9 \\
\hline Living with partner & 1173 & 7.5 \\
\hline \multicolumn{3}{|l|}{ Region } \\
\hline Northeast & 2584 & 16.4 \\
\hline Midwest & 3762 & 23.9 \\
\hline South & 5604 & 35.6 \\
\hline West & 3776 & 24.0 \\
\hline \multicolumn{3}{|l|}{ Work in more than one job } \\
\hline No & 14,275 & 90.8 \\
\hline Yes & 1431 & 9.1 \\
\hline \multicolumn{3}{|l|}{ Current smoker } \\
\hline Non-smoker & 13,103 & 83.3 \\
\hline Smoker & 2571 & 16.3 \\
\hline \multicolumn{3}{|c|}{ Second-hand smoke exposure (Any) } \\
\hline No & 11,889 & 75.7 \\
\hline Yes & 3820 & 24.3 \\
\hline \multicolumn{3}{|c|}{ Second-hand smoke exposure (Daily) } \\
\hline No & 14,187 & 90.4 \\
\hline Yes & 1509 & 9.6 \\
\hline
\end{tabular}

Source of the National Health Interview Survey (NHIS 2015), SD: Standard deviation

second-hand smoking exposure, suggesting that high educational attainment has smaller protective effect against any workplace second-hand smoking exposure for Blacks and Hispanics than Whites This was evident by the ORs larger than 1 for the interaction terms [Table 3]. 


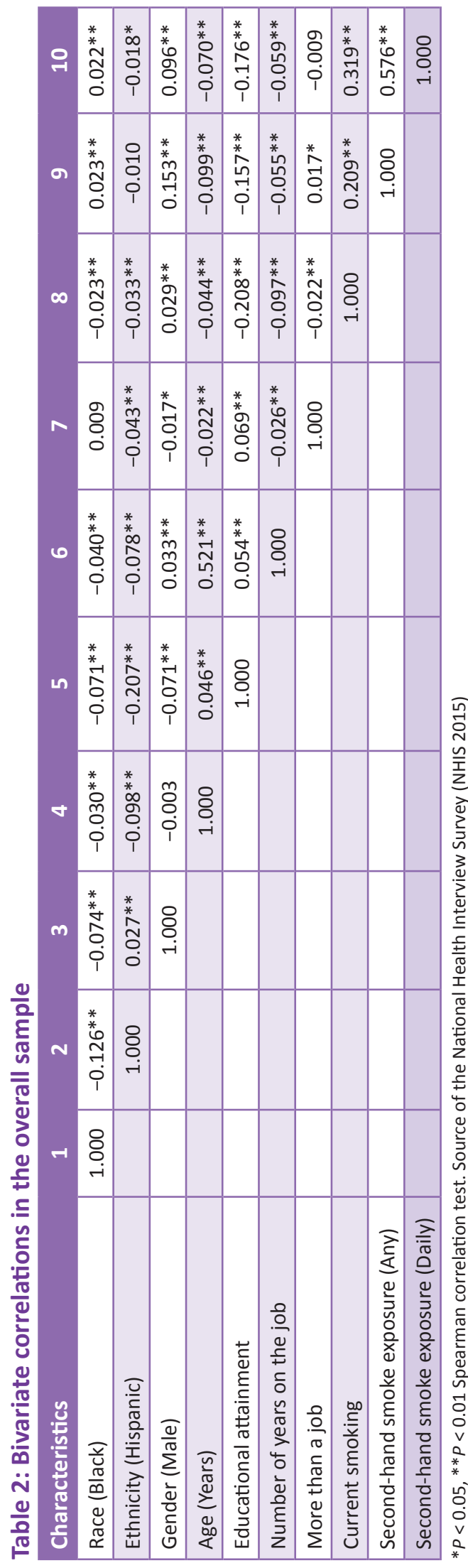

Multivariable models (Outcome: Daily second-hand smoking exposure)

Table 4 presents the summary of the results of two logistic regression models with educational attainment as the independent variable and daily workplace second-hand smoking exposure as the dependent variable. Both models were estimated in the overall sample. Model 3 only entered the main effects of educational attainment, race, ethnicity, and covariates. Model 4 also added two interaction terms between race and ethnicity with educational attainment. Based on Model 3, high educational attainment was associated with lower odds of daily second-hand smoking exposure. Model 4 showed significant interactions between race and ethnicity with educational attainment on daily second-hand smoking exposure, suggesting that high educational attainment has smaller protective effect against daily workplace second-hand smoking exposure for Blacks and Hispanics than Whites. This was evident by the odds ratio larger than 1 for the interaction terms [Table 4].

\section{Discussion}

The current study showed two main findings. First, overall, higher educational attainment was associated with lower odds of any and daily secondhand smoking exposure at work. Second, race and ethnicity interacted with educational attainment, suggesting that educational attainment has smaller protective effects against any and daily secondhand smoke exposure at workplace for Blacks and Hispanics than Whites.

Built on the MDRs, educational attainment better reduces risk of substance use for Blacks and Hispanics compared to Whites. ${ }^{[23,24,27,28]}$ That is, highly educated Blacks and Hispanics remain at high level of tobacco and alcohol use compared to highly educated Whites. The current results suggest that in a similar pattern, highly educated Blacks and Hispanics also remain at high risk of exposure to second-hand smoke. That is, highly educated Blacks and Hispanics stay at risk of tobacco-related disease, directly, and indirectly, through multiple mechanisms.

The additional health risk of high SES Blacks and Hispanics is previously described by the MDRs theory. ${ }^{[17-19]}$ Similar patterns are shown for the associations between a wide range of SES indicators and health outcomes. The effects of education and other SES indicators on obesity, ${ }^{[29]}$ depression, ${ }^{[30]}$

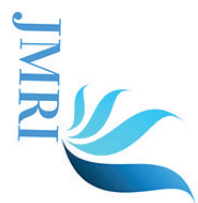


Table 3: Summary of logistic regression models on any workplace second-hand smoke exposure in the pooled sample

\begin{tabular}{|c|c|c|c|c|c|c|c|c|}
\hline \multirow[t]{2}{*}{ Characteristics } & \multirow[t]{2}{*}{ OR } & \multicolumn{2}{|c|}{$95 \% \mathrm{Cl}$} & \multirow[t]{2}{*}{$\boldsymbol{P}$} & \multirow[t]{2}{*}{ OR } & \multirow{2}{*}{\multicolumn{2}{|c|}{$\begin{array}{c}95 \% \mathrm{Cl} \\
\text { Model } 2 \text { (Model } \\
1+\text { Interactions) }\end{array}$}} & \multirow[t]{2}{*}{$\boldsymbol{P}$} \\
\hline & & \multicolumn{2}{|c|}{$\begin{array}{c}\text { Model } 1 \\
\text { (Main Effects) }\end{array}$} & & & & & \\
\hline Race (Blacks) & 1.19 & 1.07 & 1.33 & 0.002 & 0.44 & 0.24 & 0.83 & 0.011 \\
\hline Ethnicity (Hispanics) & 0.72 & 0.64 & 0.82 & 0.000 & 0.15 & 0.09 & 0.25 & $<0.001$ \\
\hline Gender (Male) & 2.08 & 1.92 & 2.25 & 0.000 & 2.08 & 1.92 & 2.26 & $<0.001$ \\
\hline Age (Years) & 0.98 & 0.98 & 0.99 & 0.000 & 0.98 & 0.98 & 0.99 & $<0.001$ \\
\hline Educational attainment (Years) & 0.92 & 0.91 & 0.93 & 0.000 & 0.88 & 0.86 & 0.90 & $<0.001$ \\
\hline Marital status & & & & 0.073 & & & & 0.143 \\
\hline \multicolumn{9}{|l|}{ Married } \\
\hline Widowed & 1.10 & 0.84 & 1.44 & 0.483 & 1.08 & 0.82 & 1.41 & 0.586 \\
\hline Divorced & 1.15 & 1.02 & 1.30 & 0.022 & 1.13 & 1.01 & 1.28 & 0.040 \\
\hline Separated & 1.02 & 0.81 & 1.30 & 0.854 & 1.02 & 0.80 & 1.29 & 0.875 \\
\hline Never married & 1.11 & 1.01 & 1.23 & 0.038 & 1.11 & 1.00 & 1.22 & 0.054 \\
\hline Living with partner & 1.22 & 1.05 & 1.41 & 0.009 & 1.20 & 1.03 & 1.39 & 0.016 \\
\hline Unknown & 1.10 & 0.38 & 3.14 & 0.861 & 1.08 & 0.38 & 3.07 & 0.890 \\
\hline Region & & & & 0.005 & & & & 0.003 \\
\hline Northeast & 1.00 & & & & & & & \\
\hline Midwest & 1.03 & 0.91 & 1.17 & 0.593 & 1.02 & 0.90 & 1.16 & 0.722 \\
\hline South & 1.03 & 0.91 & 1.15 & 0.681 & 1.02 & 0.91 & 1.15 & 0.697 \\
\hline West & 1.20 & 1.06 & 1.36 & 0.004 & 1.21 & 1.07 & 1.37 & 0.003 \\
\hline Years in the same job & 1.00 & 1.00 & 1.01 & 0.121 & 1.00 & 1.00 & 1.01 & 0.149 \\
\hline Working in more than a job & 1.24 & 1.09 & 1.42 & 0.001 & 1.25 & 1.10 & 1.43 & 0.001 \\
\hline Smoker current & 2.78 & 2.53 & 3.05 & 0.000 & 2.68 & 2.43 & 2.94 & $<0.001$ \\
\hline Race $x$ Educational attainment & & & & & 1.07 & 1.02 & 1.11 & 0.002 \\
\hline $\begin{array}{l}\text { Ethnicity } x \text { educational } \\
\text { attainment }\end{array}$ & & & & & 1.12 & 1.08 & 1.15 & $<0.001$ \\
\hline Constant & 1.15 & & & 0.376 & 2.30 & & & $<0.001$ \\
\hline
\end{tabular}

Source of the National Health Interview Survey (NHIS 2015). Cl: Confidence interval; SE: Standard error; OR: Odds ratio

anxiety, $^{[31]}$ self-rated health, ${ }^{[32]}$ and chronic disease ${ }^{[33]}$ are all smaller for Blacks and Hispanics than Whites.

Smaller effects of educational attainment on any and daily second-hand smoking exposure at work may be due to multiple factors. Due to residential segregation, highly educated Blacks and Hispanics still are more likely to live in predominantly Black and Hispanic areas, which have scarce employment opportunities. Due to labor market discrimination as well as job segregation, highly educated Blacks and Hispanics are less likely to get high paying jobs. Segregation also reduces quality of education in
Black and Hispanic areas, and quality of education is one of the many determinates of type and quality of occupation. As a result, the solution is not limited to the individual but should address structural and institutional factors that shape MDRs as a mechanism behind health disparities.

Pervasive disparities in the burden of tobacco use by race/ethnicity ${ }^{[16,34-37]}$ and $\mathrm{SES}^{[38-40]}$ exist in the US. Despite the overall decline in tobacco use, disparities by SES have increased. ${ }^{[40-42]}$ Between 1966 and 2015, smoking declined by $83 \%$ in individuals with college degree, while the decline for individuals without high school diploma was almost half (40\%). ${ }^{[4]} \mathrm{A}$ large 
Assari and Bazargan: Race, Employment, and Second-Hand Smoke Exposure

Table 4: Summary of logistic regression models on daily workplace second-hand smoke exposure in the pooled sample

\begin{tabular}{|c|c|c|c|c|c|c|c|c|}
\hline \multirow[t]{2}{*}{ Characteristics } & \multirow[t]{2}{*}{ OR } & \multicolumn{2}{|c|}{$95 \% \mathrm{Cl}$} & \multirow[t]{2}{*}{$P$} & \multirow[t]{2}{*}{ OR } & \multirow{2}{*}{\multicolumn{2}{|c|}{$\begin{array}{c}95 \% \mathrm{Cl} \\
\text { Model } 4 \text { (Model } \\
3+\text { Interactions) }\end{array}$}} & \multirow[t]{2}{*}{$P$} \\
\hline & & \multicolumn{2}{|c|}{$\begin{array}{c}\text { Model } 3 \\
\text { (Main Effects) }\end{array}$} & & & & & \\
\hline Race (Blacks) & 1.22 & 1.04 & 1.43 & 0.017 & 0.39 & 0.16 & 0.91 & 0.029 \\
\hline Ethnicity (Hispanics) & 0.60 & 0.49 & 0.74 & 0.000 & 0.14 & 0.07 & 0.27 & $<0.001$ \\
\hline Gender (Male) & 1.97 & 1.75 & 2.23 & 0.000 & 1.98 & 1.75 & 2.23 & $<0.001$ \\
\hline Age (Years) & 0.98 & 0.98 & 0.99 & 0.000 & 0.98 & 0.98 & 0.99 & $<0.001$ \\
\hline $\begin{array}{l}\text { Educational attainment } \\
\text { (Years) }\end{array}$ & 0.88 & 0.86 & 0.90 & 0.000 & 0.84 & 0.82 & 0.86 & $<0.001$ \\
\hline Marital status & & & & 0.038 & & & & 0.058 \\
\hline \multicolumn{9}{|l|}{ Married } \\
\hline Widowed & 1.19 & 0.79 & 1.80 & 0.396 & 1.17 & 0.77 & 1.76 & 0.458 \\
\hline Divorced & 1.22 & 1.02 & 1.45 & 0.031 & 1.20 & 1.01 & 1.44 & 0.043 \\
\hline Separated & 1.21 & 0.87 & 1.67 & 0.258 & 1.20 & 0.87 & 1.66 & 0.272 \\
\hline Never married & 1.08 & 0.92 & 1.26 & 0.354 & 1.08 & 0.92 & 1.26 & 0.354 \\
\hline Living with partner & 1.34 & 1.09 & 1.64 & 0.005 & 1.32 & 1.08 & 1.62 & 0.007 \\
\hline Unknown & 2.74 & 0.82 & 9.12 & 0.101 & 2.71 & 0.82 & 8.98 & 0.103 \\
\hline Region & & & & 0.373 & & & & 0.378 \\
\hline \multicolumn{9}{|l|}{ Northeast } \\
\hline Midwest & 1.08 & 0.90 & 1.31 & 0.41 & 1.07 & 0.89 & 1.30 & 0.476 \\
\hline South & 1.17 & 0.98 & 1.40 & 0.091 & 1.17 & 0.97 & 1.40 & 0.096 \\
\hline West & 1.08 & 0.89 & 1.32 & 0.426 & 1.09 & 0.89 & 1.32 & 0.400 \\
\hline Years in the same job & 1.00 & 0.99 & 1.01 & 0.989 & 1.00 & 0.99 & 1.01 & 0.987 \\
\hline $\begin{array}{l}\text { Working in more than } \\
\text { a job }\end{array}$ & 1.04 & 0.85 & 1.28 & 0.688 & 1.05 & 0.86 & 1.29 & 0.623 \\
\hline Smoker (Current) & 6.43 & 5.71 & 7.25 & 0.000 & 6.22 & 5.51 & 7.01 & $<0.001$ \\
\hline $\begin{array}{l}\text { Race } \times \text { Educational } \\
\text { attainment }\end{array}$ & - & - & - & - & 1.08 & 1.02 & 1.14 & 0.008 \\
\hline $\begin{array}{l}\text { Ethnicity } x \text { Educational } \\
\text { attainment }\end{array}$ & - & - & - & - & 1.12 & 1.06 & 1.17 & $<0.001$ \\
\hline Constant & 0.52 & & & 0.004 & 1.04 & & & 0.897 \\
\hline
\end{tabular}

Source of the National Health Interview Survey (NHIS 2015). CI: Confidence interval; SE: Standard error; OR: Odds ratio

proportion of such disparities may not be due to individuals making poor choices but higher exposure due to predatory marketing. ${ }^{[43-45]}$ In addition to the predatory marketing, flavoring, point-of-sale advertising, retail display, coupons, and discounts, ${ }^{[46]}$, racial and ethnic minorities and low SES individuals are also at an increased risk of second-hand exposure. ${ }^{[10]}$ There is a need for policies at both national and local levels that can reduce the racial/ethnic and SES tobacco disparities, particularly those that are caused by MDRs. ${ }^{[19,23,24,28,29,31,47-50]}$ There is a need to study how point of sale advertisement, discounts, coupons, and flavoring result in MDRs for tobacco use $^{[23,24]}$ and how some of these marketing strategies disproportionately target low SES Black and Hispanic ${ }^{[23,24,27,28]}$ communities. To undo racial and ethnic disparities in tobacco use, there may be a need to ban predatory marketing in low-income areas.

\section{Implications}

The results may have some policy and public health implications. There is a need for conducting 


\section{Assari and Bazargan: Race, Employment, and Second-Hand Smoke Exposure}

"impact analysis" of tobacco control policies, smoke-free laws, and marketing regulatory laws on disparities in exposure to second-hand smoke across social groups based on race, ethnicity, and SES. There is a need to conduct additional studies that can help us understand why race/ethnicity by SES people becomes susceptible to tobaccorelated illnesses. The results may help with the development of public, economic, and tobacco policies that can eliminate tobacco-related disparities, particularly those that are based on race, ethnicity, and SES. These are all strategic priorities for the Food and Drug Administration (FDA) and National Institutes of Health (NIH). Setting more restrictive national policies that tighten tobacco regulations are shown to be acceptable by the US public. ${ }^{[51]}$ This is promising and emphasizes such policies will not be found against their autonomy. ${ }^{[51]}$ Such large-scale policies may be more effective than individuallevel interventions that overemphasize individual choices (focus on behavioral change of individuals through motivation). ${ }^{[51]}$

\section{Limitations}

This study had some methodological limitations. The cross-sectional design of our data does not allow causal inferences. The outcome was measured using single-item measure. We only measured workplace second-hand exposure. Sample size was imbalanced across race and ethnic groups. Many SES indicators such as income, employment, and marital status were missing. This study did not measure health and depression. This study was limited to individual-level SES and future research could also include area-level SES. Despite these limitations, we believe this study still makes a contribution to literature.

\section{Conclusion}

In the United States, educational attainment is expected to reduce environmental exposures such as second-hand smoke at work; however, this gain depends on race and ethnicity. In the US, race/ethnicity bounds the health gains that follow educational attainment. While highly educated Whites are exposed to lowest levels of workplace second-hand smoking exposure, Blacks and Hispanics gain least from their educational attainment. As a result, we should expect additional risk of tobacco-related illnesses in highly educated middle-class Blacks and Hispanics. Policy-makers should not assume SES similarly protect all social groups against environmental exposures such as any and daily second-hand smoking exposure. Policy-makers and researchers should also try to reduce health disparities to low SES but also mechanisms that operate across all SES levels. Health disparities are also a problem with middle-class Blacks and Hispanics, which is one of the major growing sections of the US population.

\section{Authors Roles}

Shervin Assari: Conceptualization, analysis, draft, revision, and approval of the final draft.

Mohsen Bazargan: Conceptualization, revision, and approval of the final draft.

\section{Funding}

Research reported in this publication was supported by the National Cancer Institute $(\mathrm{NCl})$ of the $\mathrm{NIH}$ and FDA Center for Tobacco Products (CTP) under Award Number U54CA229974. The content is solely the responsibility of the authors and does not necessarily represent the official views of the NIH or the FDA. Bazargan is supported by the Center for Medicare and Medicaid Services (CMS) Grant 1HOCMS331621 as well as the NIH Awards 54MD008149", R25 MD007610, 2U54MD007598, and U54 TR001627. Assari is also supported by the $\mathrm{NCl}$ grant CA201415-02 (Co-PI = R. Mistry). Publicly available data set was downloaded from the NHIS website at CDC. The NHIS is funded by the CDC.

\section{Conflicts of Interest}

None.

\section{References}

1. McCarthy M. Smoking remains leading cause of premature death in US. BMJ 2014;348:g396.

2. Novick LF. Smoking is the leading preventable cause of death and disability in the United States. J Public Health Manag Pract 2000;6:6.

3. King BA, Dube SR, Tynan MA. Current tobacco use among adults in the United States: Findings from the national adult tobacco survey. Am J Public Health 2012;102:e93-100.

4. Drope J, Liber AC, Cahn Z, Stoklosa M, Kennedy R, Douglas CE, et al. Who's still smoking? Disparities in adult cigarette smoking prevalence in the United States. CA Cancer J Clin 2018;68:106-15. 


\section{Assari and Bazargan: Race, Employment, and Second-Hand Smoke Exposure}

5. Holford TR, Meza R, Warner KE, Meernik C, Jeon J, Moolgavkar SH, et al. Tobacco control and the reduction in smoking-related premature deaths in the United States, 1964-2012. JAMA 2014;311:164-71.

6. From the centers for disease control and prevention. State-specific prevalence of current cigarette smoking among adults and the proportion of adults who work in a smoke-free environment united States, 1999. JAMA 2000;284:2865-6.

7. Centers for Disease Control and Prevention (CDC). Smoking and Tobacco Use. Fast Facts Sheet; 2019.

8. Centers for Disease Control and Prevention (CDC) CFDCAP. African Americans and Tobacco Use; 2019. Available from: https://www.cdc.gov/tobacco/ data_statistics/fact_sheets/index.htm.

9. Kasza KA, McKee SA, Rivard C, Hyland AJ. Smokefree bar policies and smokers' alcohol consumption: Findings from the international tobacco control four country survey. Drug Alcohol Depend 2012;126:240-5.

10. Akhtar PC, Haw SJ, Levin KA, Currie DB, Zachary R, Currie $\mathrm{CE}$, et al. Socioeconomic differences in secondhand smoke exposure among children in Scotland after introduction of the smoke-free legislation. J Epidemiol Community Health 2010;64:341-6.

11. Lowrie C, Pearson AL, Thomson G. Inequities in coverage of smokefree outdoor space policies within the United States: School grounds and playgrounds. BMC Public Health 2018;18:736.

12. Agaku IT, Odukoya OO, Olufajo O, Filippidis FT, Vardavas $\mathrm{Cl}$. Support for smoke-free cars when children are present: A secondary analysis of 164,819 U.S. Adults in 2010/2011. Eur J Pediatr 2014;173:1459-66.

13. Greaves L, Hemsing N. Women and tobacco control policies: Social-structural and psychosocial contributions to vulnerability to tobacco use and exposure. Drug Alcohol Depend 2009;104 Suppl 1:S121-30.

14. Cokkinides VE, Halpern MT, Barbeau EM, Ward E, Thun MJ. Racial and ethnic disparities in smokingcessation interventions: Analysis of the 2005 national health interview survey. Am J Prev Med 2008;34:404-12.

15. Tran ST, Rosenberg KD, Carlson NE. Racial/ethnic disparities in the receipt of smoking cessation interventions during prenatal care. Matern Child Health J 2010;14:901-9.

16. Trinidad DR, Pérez-Stable EJ, White MM, Emery SL, Messer K. A nationwide analysis of US racial/ethnic disparities in smoking behaviors, smoking cessation, and cessation-related factors. Am J Public Health 2011;101:699-706.

17. Assari S. Parental educational attainment and mental well-being of college students; diminished returns of blacks. Brain Sci 2018;8:E193.
18. Assari S. Health disparities due to diminished return among black Americans: Public policy solutions. Soc Issues Policy Rev 2018;12:112-45.

19. Assari S. Unequal gain of equal resources across racial groups. Int J Health Policy Manag 2017;7:1-9.

20. Assari S. Education attainment and obesity: Differential returns based on sexual orientation. Behav Sci (Basel) 2019;9:E16.

21. Assari S. Parental education attainment and educational upward mobility; role of race and gender. Behav Sci (Basel) 2018;8:E107.

22. Assari S. Educational attainment better protects african American women than african American men against depressive symptoms and psychological distress. Brain Sci 2018;8:E182.

23. Assari S, Farokhnia M, Mistry R. Education attainment and alcohol binge drinking: Diminished returns of hispanics in Los Angeles. Behav Sci (Basel) 2019;9:E9.

24. Assari S, Mistry R. Educational attainment and smoking status in a national sample of american adults; evidence for the blacks' diminished return. Int J Environ Res Public Health 2018;15:E763.

25. Assari S, Mistry R, Caldwell $\mathrm{CH}$. Perceived discrimination and substance use among caribbean black youth; gender differences. Brain Sci 2018;8:E131.

26. Assari S, Mistry R, Caldwell $\mathrm{CH}$, Zimmerman MA. Marijuana use and depressive symptoms; gender differences in african American adolescents. Front Psychol 2018;9:2135.

27. Assari S, Lankarani MM. Education and alcohol consumption among older Americans; black-white differences. Front Public Health 2016;4:67.

28. Assari S, Mistry R. Erratum: Assari, S.; mistry, R. Educational attainment and smoking status in a national sample of American adults; evidence for the blacks' diminished return. Int. J. Environ. Res. Public health 2018, 15, 763. Int J Environ Res Public Health 2018;15:E2084.

29. Assari S, Thomas A, Caldwell CH, Mincy RB. Blacks' diminished health return of family structure and socioeconomic status; 15 years of follow-up of a national urban sample of youth. J Urban Health 2018;95:21-35.

30. Assari S. High income protects whites but not african Americans against risk of depression. Healthcare (Basel) 2018;6:E37.

31. Assari $\mathrm{S}$, Caldwell $\mathrm{CH}$, Zimmerman MA. Family structure and subsequent anxiety symptoms; minorities' diminished return. Brain Sci 2018;8:E97.

32. Assari S, Lapeyrouse LM, Neighbors HW. Income and self-rated mental health: Diminished returns for high income black Americans. Behav Sci (Basel) 2018;8:E50.

33. Assari S. The benefits of higher income in protecting against chronic medical conditions are smaller for

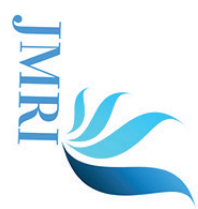




\section{Assari and Bazargan: Race, Employment, and Second-Hand Smoke Exposure}

african Americans than whites. Healthcare (Basel) 2018;6:E2.

34. Ellickson PL, Orlando $\mathrm{M}$, Tucker JS, Klein DJ. From adolescence to young adulthood: Racial/ ethnic disparities in smoking. Am J Public Health 2004;94:293-9.

35. Centers for Disease Control and Prevention (CDC). Racial disparities in smoking-attributable mortality and years of potential life lost missouri, 2003-2007. Morb Mortal Wkly Rep 2010;59:1518-22.

36. Soulakova JN, Huang H, Crockett LJ. Racial/Ethnic disparities in consistent reporting of smokingrelated behaviors. J Addict Behav Ther Rehabil 2015;4. DOI: 10.4172/2324-9005.1000147.

37. Blumenthal DS. Racial and ethnic disparities in smoking prevalence in Israel and the United States: Progress to date and prospects for the future. Isr J Health Policy Res 2017;6:51.

38. Laveist TA, Thorpe RJ Jr., Mance GA, Jackson J. Overcoming confounding of race with socio-economic status and segregation to explore race disparities in smoking. Addiction 2007;102 Suppl 2:65-70.

39. Reid JL, Hammond D, Driezen P. Socio-economic status and smoking in Canada, 1999-2006: Has there been any progress on disparities in tobacco use? Can J Public Health 2010;101:73-8.

40. Zhang X, Martinez-Donate AP, Jones NR. Educational disparities in home smoking bans among households with underage children in the United States: Can tobacco control policies help to narrow the gap? Nicotine Tob Res 2013;15:1978-87.

41. Reimer RA, Gerrard M, Gibbons FX. Racial disparities in smoking knowledge among current smokers: Data from the health information national trends surveys. Psychol Health 2010;25:943-59.

42. Rock VJ, Davis SP, Thorne SL, Asman KJ, Caraballo RS.
Menthol cigarette use among racial and ethnic groups in the United States, 2004-2008. Nicotine Tob Res 2010;12 Suppl 2:S117-24.

43. Terry-McElrath YM, Wakefield MA, Emery S, Saffer H, Szczypka G, O'Malley PM, et al. State anti-tobacco advertising and smoking outcomes by gender and race/ethnicity. Ethn Health 2007;12:339-62.

44. Keeler C, Max W, Yerger V, Yao T, Ong MK, Sung HY, et al. The association of menthol cigarette use with quit attempts, successful cessation, and intention to quit across racial/Ethnic groups in the United States. Nicotine Tob Res 2017;19:1450-64.

45. Giovenco DP, Spillane TE, Merizier JM. Neighborhood differences in alternative tobacco product availability and advertising in New York city: Implications for health disparities. Nicotine Tob Res 2019;21:896-902.

46. Anderson SJ. Marketing of menthol cigarettes and consumer perceptions: A review of tobacco industry documents. Tob Control 2011;20 Suppl 2:220-8.

47. Assari S. Blacks' diminished return of education attainment on subjective health; mediating effect of income. Brain Sci 2018;8:E176.

48. Assari S, Hani N. Household income and children's unmet dental care need; blacks' diminished return. Dent J (Basel) 2018;6:E17.

49. Assari S, Caldwell CH, Mincy R. Family socioeconomic status at birth and youth impulsivity at age 15; blacks' diminished return. Children (Basel) 2018;5:E58.

50. Assari S. Socioeconomic status and self-rated oral health; diminished return among hispanic whites. Dent J (Basel) 2018;6:E11.

51. Feliu A, Filippidis FT, Joossens L, Fong GT, Vardavas $\mathrm{Cl}$, Baena $A$, et al. Impact of tobacco control policies on smoking prevalence and quit ratios in 27 European union countries from 2006 to 2014. Tob Control 2019;28:101-9. 